S sciendo

\title{
On the Metaphysics of Internalism and Externalism
}

\author{
Alberto Voltolini \\ University of Eastern Piedmont at Vercelli
}

Disputatio Vol. 1, No. 18

May 2005

DOI: $10.2478 /$ disp-2005-0002

ISSN: 0873-626X 


\title{
On the metaphysics of internalism and externalism
}

\author{
Alberto Voltolini \\ University of Eastern Piedmont at Vercelli
}

\begin{abstract}
In this paper, I explore the consequences of the thesis that externalism and internalism are (possibly, but as we will see not necessarily, opposite) metaphysical doctrines on the individuation conditions of a thought. If I am right, this thesis primarily entails that at least some naturalist positions on the ontology of the mind, namely the reductionistic ones, are hardly compatible with both externalism and a version of internalism so conceived, namely relational internalism. Indeed, according to both externalism and relational internalism, intentionality constitutes (or at least grounds) the relational content property providing the individuation conditions of a thought, as a relation to an outer or to an inner object respectively. Yet since intentionality turns out to be a modal, hence a nonnatural, property, both externalism and relational internalism deny to thoughts at least token-identity with physical states. Finally, I will give some support to the idea that externalism and internalism must be interpreted as doctrines on the individuation conditions of a thought.
\end{abstract}

\section{Preliminaries: how externalism as a doctrine of thought individuation leads to nonreductionism about thoughts}

In recent years, many authors have maintained that both externalism and internalism are metaphysical doctrines, insofar as they concern the individuation conditions of a thought. According to this view, externalism says that a thought is individuated inter alia in terms of the entities it is about — which are external to the mind of the thinker — insofar as these entities are among its constituents. ${ }^{1}$ On the other hand,

\footnotetext{
${ }^{1}$ As is well known, traditional examples allegedly supporting externalism often involve natural kinds rather than concrete particulars. Yet, since in these examples natural kinds also work as objects of aboutness for the relevant thoughts, the
}

Disputatio, Vol. I, No. 18, May 2005 
internalism appears to deny this relational individuation condition, by claiming that only things happening inside the thinker are relevant to the individuation of a thought. I say 'appears to deny', for the above internalist claim is compatible with saying that a thought is individuated inter alia in terms of entities - again, the entities it is about seen however as entities internal to the mind of the thinker. ${ }^{2}$ Let me call this claim the distinctive thesis of relational internalism. ${ }^{3}$ We will come back to relational internalism in Section 3 below.

distinction between concrete particulars and natural kinds is irrelevant for the purposes of my present definition of metaphysical externalism. Moreover, as Section 4 will make explicit, I intend this definition of externalism qua metaphysical doctrine as broad enough to cover cases not only of natural, but also of social, externalism, according to which thoughts are taken to be constituted by public meanings. This is why I limit myself to generically speaking of external entities of aboutness for a thought.

${ }^{2}$ In defining externalism and internalism, I speak of items of aboutness as respectively external vs. internal to the mind rather than to the body or to the brain of the thinker. For the time being, this allows me to remain neutral with respect to the doubts Farkas 2003 has raised against the fact that an individuation of a thought in terms of entities internal either to the body or the brain of the thinker is legitimately to be labelled as internalist. Yet I will consider the general issue of whether an individuation of an intentional state in terms of inner objects is legitimately to be labelled internalist later (see fn. 32 below).

${ }^{3}$ I speak directly of individuation conditions of the thought rather than, as is often done in the literature (cf., e.g., McGinn (1989, 7)), of individuationdependence. For one is usually tempted to characterize the notion of dependence in modal terms: an entity $A$ depends on an entity $B$ iff necessarily, if $A$ exists, then $B$ exists as well (cf., e.g., Thomasson $(1999,25))$. Yet, as Fine has convincingly shown, modality hardly captures essence, which is what individuation conditions provide. Cf. Fine 1995. To be sure, one may distinguish between two forms of dependence, individuation-dependence and existence-dependence, which is what the previous modal definition captures. Cf. Edwards (1994, 17fn.16). Yet it seems to me that matters are clearer if, as far as individuation conditions are concerned, one avoids speaking of dependence altogether. Indeed, saying that a thought depends on its objects of aboutness for its existence leaves the possibility open that it is directly constituted by singular senses, namely senses which in their turn depend on those objects of aboutness for their individuation, rather than by such objects themselves. Also in such a case, one is thus entitled to speak of singular thoughts, that would however be made of singular senses — a la Frege — rather than of objects themselves — à la Russell. As everybody knows, this neo-Fregean possibility has been exploited by Evans 1982. Yet saying that a thought depends on its objects of aboutness for its individuation leaves open the very same possibility. 
For the time being, consider externalism. Saying that a thought is individuated inter alia in terms of the entities it is about actually synthesizes two distinct sub-theses: a) a thought is individuated inter alia in terms of its semantic features, i.e., of its having content; b) (having) content is individuated at least in terms of the entities the thought that content is the content of is about. ${ }^{4}$

If thesis a) is correct, it has already implications on the ontology of the mind. For it rules out a position such as Davidson's anomalous monism. As is well known, according to Davidson, even if there are no such things as (strict) laws that connect the realm of the psychological with the realm of the physical — 'bridge laws' such as psychophysical laws as it were - an intentional state is token-identical with a physical state. ${ }^{5}$ The no 'bridge laws' - thesis can combine itself with the token-identity thesis insofar as talking about the mental merely gives a specific way of describing states which can alternatively be described also physically. In other terms, mental language is a particular pattern of description of events by means of which we carve states that can be singled out also by other patterns of description, other languages, such as the physical language. Now, this position entails that ascribing content to a thought can at most yield a hermeneutically indispensable way of describing that thought in mental terms. According to this position, indeed, there are no such things as content properties. Yet when we ascribe contents to thoughts, we identify them by means of a pattern of description we cannot avoid if we want to account for things like rationality and responsibility in human behaviour. ${ }^{6}$

\footnotetext{
${ }^{4}$ One might here object to my saying that the thesis in question is the synthesis of the two distinct sub-theses a) and b). For these theses involve the notion of a thought's content, which actually does not figure in the thesis in question. Thus, one might well say that the thesis in question does not appeal to the notion of content, which may be found problematic for its disputable reifying import. (I owe this suggestion to Elisabetta Sacchi.) Yet note that the equivalence of the individuation thesis of a thought in terms of its object with the conjunction of the sub-theses a) and b) may be held independently of the interpretation of content as a certain thing. As a result, even if one rejected the reifying interpretation of content, the thesis in question would still have the nonreductionist consequences I will draw in what follows.

${ }^{5}$ Cf. Davidson 1980b.

${ }^{6}$ This is what Davidson explicitly theorizes about intentionality. He acknowledges intentionality as a basic feature of an intentional act - more precisely, as the distinguishing feature of the mental: cf. Davidson (1980b, 211). Yet for him this is merely
} 
Thesis a), however, is not a thesis on the identification conditions, but precisely on the individuation conditions of a thought. If a) holds, then thought content is not a merely hermeneutically essential way of describing a thought, but rather an ontologically essential property of the thought. Thus, pace Davidson thesis a) entails that there are such things as genuine mental properties. As a result, if thesis a) is correct, then, since metaphysical externalism is primarily made out of that thesis, it is incompatible with Davidson's anomalous monism. ${ }^{7}$

Content's being a property relevant for the individuation a thought - the gist of thesis a) — risks to have further ontological consequences, if not entirely nonnaturalist, yet definitely of a nonreductionist kind. Let me well put aside Davidson's anomalous monism. It remains that, if a thought has one such content property, how can it can be token-identical with a physical state? In fact, how can a state that is physical have a content property?

To be sure, by itself this doubt is ungrounded. First, as many have maintained, ${ }^{9}$ nothing prevents a content property from being a natural one, hence from being a property that also a physical state may possess. Moreover, even if it were a nonnatural property, by itself nothing rules out that also a physical state possesses it. Consider indeed the following. If there are such things as modal properties, they can be taken as the paradigmatic case of nonnatural properties. As Kim has convincingly maintained, the dividing line between a naturalistic and a nonnaturalistic approach towards a (kind of) property lies in holding vs. rejecting supervenience of such a property on physical properties. ${ }^{10}$ Now, as Williamson has shown, modal properties do not supervene on qualitative physical properties. In other

tantamount to saying that we are forced to describe an event as endowed with intentionality when we describe it qua intentional: cf. Davidson (1980a, 4, 13-5).

${ }^{7}$ This of course leaves open the possibility that other forms of externalism are compatible with Davidson's theory (for instance, nomological externalism, according to which a thought is merely causally dependent on its objects). Yet this does not really save matters, for, as I will try to show in Section 4 of this paper, metaphysical externalism is the best form of externalism.

\footnotetext{
${ }^{8}$ For this doubt, cf., e.g., Jacquette (1994, chap.4).

${ }^{9}$ Cf., e.g., Dretske 1981, Fodor 1987, Millikan 1984.

${ }^{10}$ Cf. $\operatorname{Kim}(1998,15)$.
} 
terms, things qualitatively alike may differ modally. ${ }^{11}$ Hence, modal properties are nonnatural. Yet, physical states may well have such properties. So, the fact that a certain state possesses a modal property does not by itself rule out that it is token-identical with a physical state. Let us thus well suppose that a content property be a nonnatural property if it does not supervene on a physical property. Yet, a reductionist may well conclude, the intentional state that has that content property would not be prevented from being token-identical with a physical state. ${ }^{12}$

Yet, the nonreductionist might further remark, if thesis a) is correct, the property in question is an essential one for the mental entity that has it, namely a thought. Now, Fine has shown us that essence is stronger than modality, hence of necessity: an essential property is not simply a necessary property of an object, but rather is a constitutive property for it, or even better, a property whose predication to an item is true in virtue of the identity, or the nature, of such an item. ${ }^{13}$ Thus, a content property is a constitutive property of a thought. But if that property were nonnatural, one might put forward the following, Descartes-inspired, doubt: how could such a property also be essential for a physical entity? Can a physical entity be essentially contentful, that is, be contentful in virtue of its nature, if having a content means instantiating a nonnatural property? ${ }^{14}$

It is here that, by adding thesis b) to thesis a), externalism properly enters the stage. At first sight, adding b) to a) seems to support reductionism. According to b), whenever there is an entity a certain thought is about, the content of this thought is constituted inter alia by

${ }^{11}$ Cf. Williamson $(2000,204)$.

${ }^{12}$ For this line of reasoning, cf. Gibbons $(1993,66,79)$.

${ }^{13}$ Cf. Fine $(1995,273)$

${ }^{14}$ For the Cartesian argument to the effect that difference in essential properties entails difference in the individuals having such properties, cf. obviously Descartes' reply to Hobbes, in 1985. Following Gibbons (1993, 64-5), one might reply that, since a principle of individuation does not entail essentialism, thoughts may be individuated in terms of their content properties and yet be token-identical with physical states. Yet, according to me thesis a) precisely means that a content property is a constitutive property of a thought. For it says that a thought is individuated by a content property insofar as it is constituted by it. Since, as Gibbons himself admits, a constitutive property of a thing is essential for that thing (ib., 69-71), the above anti-reductionist result again follows. 
that entity: it is a singular content. Given a), this turns out to be the content of a singular thought, a thought precisely individuated in terms of the entity its content itself is also individuated. ${ }^{15}$ Having a singular content, the content that individuates a singular thought, is thus a relational property, a property that involves an entity among its constituents. As a result, the above Cartesian doubt seems to be put apart. To be sure, if a nonnatural property is had essentially by something, that something can hardly be a natural entity like a physical state. Yet why should a relational content property be nonnatural? Definitely, nothing makes relational properties as such nonnatural. Insofar as this is not the case, mental as well as physical states cannot only have relational content properties, but also have them essentially. A content property can thus be a relational property that also a physical state has essentially. Hence, the externalist reductionist will conclude, nothing hitherto prevents intentional states from being tokenidentical with physical states.

Yet things become more complicated for the externisticallyoriented reductionist once one reflects upon the consequences of adding b) to a). For b) says that content, hence thought, is individuated in terms of the entity that thought is about. Yet it does not say that this entity must exist - or at least, that it must exist in a physically relevant sense. Now, it can hardly be the case that a physical state is individuated in terms of a relational content property that involves an entity not existing in that sense. For that property sounds again nonnatural. To be sure, as we have seen above, physical states may well have nonnatural properties. Yet it is hardly the case that they have such properties essentially, in the above Finean sense to the effect that they have constitutive properties, properties truly predicated of them in virtue of their identity, or nature. How can a physical entity have a non-physical property in virtue of its nature of physical being? Hence, we finally have that a physical state cannot even be token-identical

${ }^{15}$ Otherwise the content (as well as the thought) is general. Cf. McDowell $(1998,482)$. I take the externalist individuation thesis as regarding both type and token intentional states. Recanati (1993, 214-5) distinguishes this version of externalism from a weaker one, in which objects of aboutness enter into the individuation conditions only of thought types, not of thought tokens. Yet, since the individuation conditions supply a thought with an essential property, I hardly understand how two thought tokens allegedly differing in their essential properties can instantiate one and the same type. For, whereas the first token is individuated in terms of the entity it is about, this does not hold for the second. 
with the intentional state that has a singular content property essentially. If an intentional state has an essential property that a physical state fails to have, the former state cannot be even token-identical with the latter state. Thus, given this individuation of a thought in terms of its possibly being about actually non (spatiotemporally) existing items, externalism as a doctrine on the individuation conditions of a thought entails nonreductionism about intentional states.

To begin with, I may have thoughts about an abstract object, e.g., the number 9. Insofar as 9 is involved in the individuation conditions of the (contents of) those thoughts, such thoughts are singular. ${ }^{16}$ Yet since 9 is an abstract object, if it exists, it exists in a non-spatiotemporal way. Hence, the relational content property that involves it hardly is a 'naturalistically correct' one. For no natural relation affects abstract entities. As a result, the thoughts that essentially have that property cannot be token-identical with physical states, whose physicality prevents them from having that property essentially.

Moreover, abstract entities are nonexistent entities only in the sense that they are non-spatiotemporal. Yet in another sense they are genuinely existent entities: though non-spatiotemporal, they are actual entities, entities that belong to the domain of the actual world. So, they are not real examples of genuinely nonexistent objects, that is, of utterly unactual entities. To be sure, such putative entities have often raised many perplexities. Yet this perplexity seems to me ungrounded. There are utterly sane examples of such entities, namely possible entities: items that, although they do not actually exist, might have existed, i.e., exist in possible worlds different from the actual one. Take the actually nonexistent offspring of two actual gametes. This is a possible object $O$ which is a full-fledged unactual entity. For $O$ is individuated in terms of an actually uninstantiated individual essence, that is, a property which, although it is actually had by nothing, must be possessed by a certain individual in all the possible worlds in which this individual exists, and may be possessed by such an individual only. ${ }^{17}$

${ }^{16}$ The possibility of singular thoughts 'directed' upon abstracta has been envisaged also by Evans, in the context however of a theory according to which singular thoughts are individuated in terms of singular senses rather than in terms of objects of aboutness themselves. Cf. fn. 3.

17 For this definition of an (actually uninstantiated) individual essence, cf. Rosenkrantz (1985/6, 199-200). Of course, this example may be controversial. Is a property like being the offspring of gametes $G$ really a case of an individual essence? Is it 
So, suppose that there is a thought 'directed' upon such an object. If this object is a full-fledged entity, we have that even though it does not exist, the thought in question is individuated in terms of it. Insofar as externalism is the doctrine that the (content of a) thought is individuated in terms of the object it is about, this thought may well fall under an externalist characterization. Indeed, a further Twin-Earth case can be easily imagined in which me and my twin have different thoughts insofar as they are respectively 'directed' upon $O$ and $O *$, the possible offspring of two actual twin-gametes of $O$ 's gametes. Now, a relational content property involving a genuinely nonexistent item is a nonnatural property. If that property is essential for a thought, it can hardly be essential for a corresponding physical state. So again, that thought and this state can hardly be token-identical.

Note that this antireductionist result has been obtained by exploiting the fact that the above conception of externalism as a metaphysical doctrine involves the notion of object of aboutness: entities external to the mind of the thinker are indeed mobilized in the individuation of a thought insofar as that thought is about those entities. Thus, what has been shown is that, if there are (genuinely) nonexistent objects of aboutness, then, according to the above conception of externalism, thoughts cannot be token-identical with physical states.

To be sure, a reductionistically-oriented externalist may remain unmoved by the above reasoning. First of all, as I have already underlined, an ontology that acknowledges nonexistent entities has generally been taken as clumsy. As a result, thoughts that are prima facie 'directed' upon genuinely nonexistent beings have been often redescribed as general, rather than as singular, thoughts: that is, as thoughts that are no longer individuated in terms of objects of aboutness. ${ }^{18}$ Hence, insofar as externalism is a theory on the individuation conditions of a thought, it has been generally supposed that such

not possible that distinct individuals come out of one and the same fertilized egg? Yet if this example raises perplexities, just change it with other more suitable ones. In 1984, Rosenkrantz has proposed cases of actually uninstantiated individual essences individuating possible mereological sums, i.e., possible compounds of actual elements. I have tried to refine the biological example in Voltolini 2000.

${ }^{18}$ Cf. McDowell (1998, 475-6, 482-3). 
thoughts do not fall under an externalist categorization, but merely rather under an internalist one. ${ }^{19}$

Moreover, in response to the nonreductionist, a reductionisticallyoriented externalist might even put her ontological perplexities as regards nonexistent entities aside. For, independently of whether those entities are genuine entities, this externalist might remark, they can hardly be objects of aboutness, i.e., objects which a thought is 'directed' upon. For intentionality, the relation of being about or 'directed' upon that subsists between the thought and its object, cannot but be a 'naturalistically correct' relation holding between existing entities.

Of course, this reply would force our externalist also to reject the idea that thought of abstracta are externalistically individuated. For, insofar as no 'naturalistically correct' relation affects abstracta, she should conclude that also thoughts of abstracta are not about such objects and therefore cannot be individuated in terms of them.

As a result of this reply, the reductionistically-oriented externalist might go on saying, no nonreductionist conclusion regarding externistically individuated thoughts would have still been assessed. For, if intentionality is a 'naturalistically correct' relation, it can be essential for a thought and yet that thought may well be token-identical with a physical state.

Yet definitely, this reply not only leaves the dispute open, but it allows the nonreductionist to put forward her position quite independently of the controversial ontological issue regarding nonexistent entities. Let us put aside, the nonreductionist retorts, the issue of

${ }^{19}$ Cf., e.g., Edwards (1994, 17-23). As Barry C. Smith made me note, however, this might be not entirely correct. For Evans' theory of singular thoughts might allow for singular thoughts of possibilia. First of all, Evans is tempted to fix as a necessary condition of a singular thought not that that thought be actually, but that it merely be possibly controlled by an information-link with its object (as Evans literally says, the subject must merely be disposed to have her thought so controlled: cf., e.g., (1982, 216)). Now, thoughts about possibilia can fit such a requirement. Moreover, a thought 'directed' upon a possibile might satisfy Evans' 'knowing which'requirement, according to which a thought may be singular, insofar as its subject knows which object she is thinking about (for this requirement, cf. Evans (1982, 107)). For if a description picking out the individual essence (on this notion, see fn. 17) of that possibile is available to that subject, then that subject is able to discriminate that possibile from all other objects. (I thank Elisabetta Sacchi for having clarified to me many details concerning Evans' theory of singular thoughts.) 
which entities are the correct righthand-side members of the intentionality relation. If the externalist states that a thought is individuated in terms of the entities it is about, then she must acknowledge that intentionality cannot but hold necessarily of that thought. Put differently, the externalist theory of thought individuation legitimates the glorious old claim that intentionality is an internal, i.e., a necessary act-object relation, not an external, i.e., a contingent, such relation. This opens the way to accept once more the idea that intentionality is a nonnatural relation, and hence, the nonreductionist claim about intentional states. Let me explain.

To begin with, if for a thought being inter alia constituted by the entity it is about supplies it with an essential relational content property, then the relevant relation it entertains with that entity is also essential for it. This relation precisely is intentionality, namely the thought's being about, or 'directed' upon, that object. Indeed, at least when the intentional state is an objectual attitude - i.e., a mere thought of an object — to say that the state has a certain relational content property involving an object is the same as saying that it bears intentionality to that object. So, intentionality is essential for that state. Whereas, when the intentional state is a propositional attitude a thought that so-and-so is the case — then the relational content property that provides the individuation conditions of such a state definitely is more complex than intentionality (for it involves other entities, e.g., properties). Yet insofar as that content property is again a relation to a certain object as the object of that state, intentionality grounds it as well, as a necessary condition for it. Indeed, no thought may have that relational property without bearing intentionality to the object constituting (inter alia) that property. ${ }^{20}$ Hence, if that property is essential for that state, so is intentionality.

\footnotetext{
${ }^{20}$ Put differently, intentionality of content — the property of having a certain propositional content - presupposes intentionality of reference - the property of being about a certain thing. For this terminology, cf. $\operatorname{Kim}(1996,21)$. Note that the converse does not hold. Since objectual attitudes may well exist independently of propositional attitudes (cf. Bonomi $(1983,96)$, Simons $(1983,81)$, Crane $(2001,31)$ ), there may be states that have intentionality of reference without having intentionality of content. Incidentally, note also that the fact that propositional attitudes have intentionality of content does not yet involve that that property is also a relation to content, taken as a genuine entity. This property is relational insofar as it is constituted by an object, the object the attitude bears intentionality of reference to. Yet this does not entail that content is another entity that attitude is in relation with.
} 
Now, it may be the case that essence does not coincide with necessity, as Fine claims. Yet the former definitely entails the latter. So, the thought bears not only essentially, but also necessarily, intentionality to its object. Now, being a necessary relation does not by itself rule out that intentionality is a 'naturalistically correct' relation. For there are a host of natural properties that are possessed by individuals necessarily (think, e.g., of the property of having a certain DNA string). Yet being a necessary relation excludes that intentionality be identified with all those candidates that usually come to one's mind when one is aiming at naturalizing it - namely, a causal or an evolutionary relation. ${ }^{21}$ For these definitely are external, not internal, relations. So, the fact that intentionality is a necessary relation at least undermines the plausibility of the idea that it is a 'naturalistically correct' relation. Insofar as this is the case, the road is once more open for conceiving it as a nonnatural relation.

If this were the case, moreover, the conclusion it has been already achieved before, namely that metaphysical externalism involves nonreductionism about intentional states, would be confirmed, quite independently of the issue regarding the existential status of the righthandside relata of intentionality. For, insofar as intentionality is a nonnatural relation, and moreover it constitutes, or at least grounds, the relational content property that an intentional state has essentially, then that state cannot be token-identical with a physical state. For a physical state cannot have a nonnatural property as one of its essential properties.

\section{The main argument: how to prove that intentionality is a nonnatural relation, hence that nonreductionism for an externalistically individuated thought holds}

Yet did I not run too fast in ruling out reductionist externalism? By holding that intentionality is an internal relation, I have merely shown that ordinary candidates for it put forward by reductionist externalists do not work, for they are external relations. Yet, as I have acknowledged above, I have not managed to show that there absolutely are no 'naturalistically correct' internal relations that can be equated with intentionality.

\footnotetext{
${ }^{21}$ As respectively maintained by the authors quoted in fn. 9 .
} 
The main problem for reductionist externalism, however, is raised not by the fact per se that intentionality holds necessarily for a thought, but rather by what this fact is intended to show, namely that intentionality is really a nonnatural relation in itself. Since, moreover, intentionality either constitutes, or at least grounds, the relational content property that provides the individuation conditions of a thought, it is an essential property for the thought. Hence, as I repeatedly said, it makes a thought irreducible to a physical entity. So, the main argument in support of the view that externalism, seen as a doctrine on the individuation conditions of a thought, entails a nonreductionist conception of thoughts, is the argument that proves that intentionality is a nonnatural property. Let me therefore pass on to saying how the nonnaturality of intentionality can effectively be shown.

As we have seen above, insofar as intentionality is essential for a thought, it also holds necessarily for it. Now, the necessity of intentionality for a thought consists in the fact that the act cannot fail to be about its object. But what does it mean to say that the thought cannot fail to be about its object? If one looks deeply at the matter, it is improper to think that intentionality is a special relation of 'directedness,' aboutness, which, unlike the ordinary relation of directedness, holds necessarily between its members - the thought and its object. Rather, it seems to me that the very saying that the thought cannot fail to be about its object means that the thought depends on the object for its existence. If there were no such object, there would not be that thought either. This further means that intentionality minimally is a specific dependence relation that is at least one-sided: ${ }^{22}$ at least the thought depends on its very object. ${ }^{23}$ Now, a dependence relation is

${ }^{22}$ For this notion, cf. Mulligan-Smith (1986, 117-8). The same notion also occurs in Thomasson $(1999,35-6)$ under the label of 'rigid dependence.' I here stick to the minimal thesis that intentionality is a one-sided dependence relation of the thought over its object. In point of fact, fans of Brentanism can hold the more radical thesis that intentionality is a mutual dependence relation, in that not only the thought depends on its object, but also the object depends on the thought that thinks it (this is the thesis of the intentional in-existence of the object).

${ }^{23}$ I say that intentionality minimally is a (specific) dependence relation in order to stress the common feature it shares with other ontologically relevant relations. Take for instance authorship. As we say that a thought is a thought of an object, we also say that a work of art is a work of someone, namely its author. Indeed, authorship can precisely be conceived as a work-author specific dependence relation: necessarily, if a work of art exists, then its author exists as well. Cf. Thomasson (1999, 35-6). But also 
intrinsically modal: to say that $A$ depends on $B$ means that necessarily, if there is such a thing as $A$, then there also is such a thing as $B .{ }^{24}$ As I said above, a modal relation definitely is a nonnatural property. As already recalled, modal properties do not supervene on qualitative nonmodal properties, and nonsupervenience is the hallmark of the nonnatural: for a property, non-supervening on physical properties is a sufficient condition for its being nonnatural. Thus, a thought having intentionality really has a nonnatural property.

So again, this property occurs in or at least grounds the relational content property providing the individuation of the thought. Hence, intentionality is essential for the thought. As a result, the thought hardly is token-identical with a physical state. For a physical state can peacefully have a nonnatural property, but cannot have it as its essence, as a property that constitutes its very nature. ${ }^{25}$

the ontological privacy of a thought, if there is such a thing, is one such relation: no thought that is not the thought of somebody; that is, a thought would not exist if its bearer did not exist either. I recall this latter example not accidentally. For it shows that being a specific dependence relation is merely a necessary, but not a sufficient, condition for intentionality. In particular, by knowing that a thought specifically depends on another entity, I do not know yet whether the relation holding between the thought and that entity is either intentionality or privacy.

${ }^{24}$ I formulate this dependence claim in these terms rather than in the standard existential terms - 'necessarily, if A exists, then B exists as well' — in order not to prejudge the possibility that intentionality be a relation to existent as well as to nonexistent beings. Given this possibility, what holds necessarily is that if there is a certain thought, then there also is, among the overall domain of the objects of discourse, the object it is about. Yet, as I have said before, my point would remain untouched even if it were ultimately shown that there are no nonexistent objects of aboutness.

${ }^{25}$ One might here wonder whether this nonreductionist result might have been more easily obtained by simply saying, in a strict Cartesian style, that a thought cannot be token-identical with a physical state in that, unlike the latter, it essentially is a thought. My reply to this question is, first, that, unless one has a theory regarding what it is for something to be a thought, it is simply undecidable whether a physical state cannot be essentially a thought. For example, if being a thought turned out to be a natural property, it might even be the case that a physical state were essentially a thought. Secondly, since metaphysical externalism is one such theory, i.e., a theory that says that a thought inter alia is what has intentionality to something, it can account for why a physical state cannot be essentially a thought. This cannot be the case because, according to such theory, i) being a thought precisely is, inter alia, having intentionality to something, and, moreover, ii) intentionality is an essential and iii) a nonnatural property of a thought. 
A caveat. On behalf of the reductionistically-oriented externalist, one might envisage the following retreat. On the basis of the previous remarks, the above externalist may accept that intentionality is nonnatural. Yet she might still maintain that, in order to have a thought endowed with intentionality, some natural relation or other must subsist between that thought and (relevant portions of) the external environment. Thus, although intentionality is nonnatural, it has some thought-object natural relation as a necessary condition. ${ }^{2}$

To be sure, holding that intentionality is a nonnatural relation does not rule out this possibility. Yet if one further accepts that intentionality is a relation that may involve abstracta as well as possibilia as its righthand-side relata, as I suggested in the previous Section, then there is no chance for any natural relation to give necessary conditions of intentionality. Definitely, since both abstracta and possibilia are causally inert entities (necessarily and contingently inert respectively), one may think of them without that one's thought stands in any natural relation with them. Moreover, even if one disregarded abstracta and/or possibilia as objects of aboutness, the retreat in question would at most establish that intentionality is generically grounded in natural relations. In point of fact, holding that intentionality is a nonnatural relation excludes that the existence of one such thought-object natural relation be a sufficient condition of intentionality. ${ }^{27}$ For, as we have seen in the previous Section, a property is nonnatural if it does not supervene on any natural property. Thus, intentionality's being a nonnatural relation at most allows that it is not possible for it to be instantiated without that some natural property or other is instantiated as well. For this generic grounding is well compatible with nonsupervenience. ${ }^{28}$

Note finally that intentionality's being both a nonnatural and an essential property for a thought leads to a radical antinaturalist, not merely to a nonreductionist, position on intentional states. Theoreti-

${ }^{26}$ I thank Bill Child for having made me see this point. For this thesis, cf. Bach $(1987,12)$. Moreover, Evans holds something very similar when he suggests that the information-link between an object and the thought dependent on it is a necessary condition for the existence of such a thought. Cf. Evans 1982. (I say 'suggests' and not 'holds,' for in point of fact Evans also presents a weaker version of the necessary conditions of a singular thought: cf. fn. 19.)

${ }^{27}$ I have argued for the nonnaturality of intentionality along these lines in Voltolini 2002.

${ }^{28}$ See the following footnote. 
cally speaking, even if the ontological reductionism put forward by the token-identity theory proved to be false, one may retreat to a weaker naturalist position, holding that, although intentional states are not token-identical with physical states, they supervene on them: no difference between intentional states without different between physical states. Yet, if no natural property is a sufficient condition for intentionality, and intentionality is essential for a thought, then a thought is not only prevented from being token-identical with a physical state, but also from supervening on it. ${ }^{29}$

This notwithstanding, not only mere antireductionists claiming that mental states are not token-identical with physical states, but also antinaturalists holding the more radical thesis that mental states do not even supervene on physical states, may happily acknowledge that the former states are generically grounded in the latter ones. For this merely amounts to saying that in order for a mental state to obtain, some physical state or other must obtain as well. ${ }^{30}$ Only strict Cartesians would deny this.

\section{How to apply this moral to internalism}

To be sure, an internalist will happily accept the result we have hitherto obtained, namely that externalism qua metaphysical doctrine involves nonreductionism about intentional states. For it may help her to face against externalism precisely from a strongly naturalistic standpoint:

\footnotetext{
${ }^{29}$ Interestingly enough, this supervenience failure of thoughts on physical states is proved independently of the traditional argument based on the well-known Twin Earth thought-experiment. As we have seen, the proof relies on the following premises: a) if intentionality is a modal property, it is a nonnatural property b) intentionality is essential to a thought c) if something has a nonnatural property among its essential properties, it cannot supervene on physical states. Since this proof is independent of the Twin Earth thought-experiment, it remains untouched by the troubles that allegedly affect that experiment (such as that that experiment does not amount to a genuine metaphysical possibility).

${ }^{30}$ According to Kim, this amounts to the first conjunct of the thesis that the mental supervenes on the physical. To reformulate it precisely in Kim's terms, this conjunct says that necessarily, for any mental property $M$, if anything has $M$ at time $t$, there exists a physical base property $P$ such that it has $P$ at $t$. Yet in order for this supervenience thesis to hold, also its second conjunct must be true, namely the sentence that says that (necessarily) anything that has $P$ at a time has $M$ at that time. Cf. $\operatorname{Kim}(1998,9)$.
} 
since externalism involves antireductionism and antireductionism is (for the internalist) wrong, then the worse for externalism.

In actual fact, however, her enthusiasm may be unjustified. For the problem I have just raised to externalists also risks to affect internalism.

Let me preliminarily note that, taken as a theory on the individuation conditions of a thought, internalism has not to be described in terms opposite to externalism, that is, in non-relational terms. As I hinted at in the first Section, a thought internalistically conceived can be individuated in terms of entities it is about which are not external to the mind but internal to it. By claiming that inner objects are entities that in-exist in the thought itself, the old Brentanian phenomenological tradition contributed to make such objects rather obscure entities. Yet, an internalist may well acknowledge, there is no real mystery here: typically, inner objects are for the internalist mere representational elements (words of Mentalese, as some would say) ultimately located in the brain. ${ }^{31}$ Insofar as this is the case, the content property of an internalistically conceived thought may well be conceived in relational terms, as involving inner objects of the above kind. Moreover, given that such objects ultimately are brainy items, they are full-fledged actual entities.

Now, insofar as relational internalism says that a thought may be individuated in terms of the inner objects it is about, then an internalist has to accept that this individuation does not rule out intentionality, but merely makes it a relation of aboutness to inner objects.

At first blush, an internalist may see here no dramatic problem. That individuation, she will concede, makes intentionality again a necessary and not a contingent relation for the thought. Yet, by itself, intentionality's being a necessary relation does not rule out that this relation is 'naturalistically correct.' It merely rules out certain candidates for being that relation, seen this time as relation to inner objects - e.g., computational or anyway merely syntactic relations. ${ }^{32}$ For again these candidates are only external, but not internal, relations.

Actually, moreover, the fact that a relation to an inner object is taken by the internalist to be a 'naturalistically correct' property typically makes her pay no attention to describing internalistically conceived content properties either in relational terms — as relations

\footnotetext{
${ }^{31}$ Cf., e.g., Fodor 1982.

${ }^{32}$ As suggested, e.g., in Chomsky (1992, 223-4).
} 
to inner objects — or in monadic terms — as intrinsic properties of thoughts. For an internalist, to say that a thought has content insofar as it is related to an inner object or insofar as it is merely contentful (taking 'being contentful' as denoting a type of monadic properties) seems to amount to the same thing.

To my mind, however, if internalism is taken to be a theory on the individuation conditions of a thought, there is a striking difference between its relational and its non-relational formulation. For, since relational internalism accepts intentionality as an internal relation of the thought to inner objects, either that relation will be identical with the relational content property providing the individuation for the relevant thought or it will ground that property. Hence, intentionality will again be essential as well as necessary for such a thought. As a further result, also relational internalism construes intentionality as a dependence relation of the thought on its objects, specifically inner objects. Hence, also relational internalism takes intentionality as a modal, therefore as a nonnatural, relation. So, since for relational internalism intentionality is essential for a thought, relational internalism again entails a nonreductionist view on the mental. For such a thought cannot again be even token-identical with a physical state, which is certainly not individuated in terms of a nonnatural property.

As a final result, therefore, if one wishes to stick to a reductionistic conception of intentional states, she can be neither an externalist nor a relational internalist; she can only be a monadic internalist. It is another question, of course, whether one may develop a successful monadic internalist conception of intentional states. ${ }^{33}$

\footnotetext{
${ }^{33}$ To be sure, if one defined internalism as a doctrine holding that an intentional state is to be individuated in merely intrinsic terms, by means of non-relational properties of the thinker (as Segal 2000 for instance does), then metaphysical relational internalism would turn out to be on a par with metaphysical externalism: both doctrines hold that an intentional state is to be individuated in extrinsic, i.e., relational, terms. In this perspective, that in relational internalism the objects contributing to the state's individuation are inner (perhaps ultimately brainy) does not rule out the fact that this individuation is made in terms of objects, as in metaphysical externalism.

In this respect, a really internalist perspective is just the monadic one. It thus becomes fundamental for one to be internalist not to be even a crypto-relational one, as Crane 2001 instead turns out to be. To be sure, according to Crane one may individuate a thought in terms of its intentional object and still be an internalist. For the fact that these objects are mere façons de parler makes intentionality be not a
} 


\section{Why externalism vs. internalism have to be conceived as doctrines of thought individuation}

At this point, a reductionistically-oriented philosopher may wonder whether she is obliged to endorse internalism (whether relational or non-relational) as well as externalism as metaphysical doctrines about the individuation conditions of a thought. Insofar as they are taken as such, externalism and internalism involve essentialist theses about the nature of thoughts. Yet why should one hold so strong versions of externalism and internalism? Are there no weaker versions?

Definitely, there are such versions. The first weaker alternative strategy consists in taking externalism and internalism as opposite doctrines that respectively see vs. fail to see the thought's external objects as yielding not individuation, but mere existence, conditions for that thought: necessarily, if that thought exists, there also are its objects. ${ }^{34}$ On its turn, this necessity operator can be meant either in metaphysical or in nomological terms. Accordingly, the existential dependence of the thought upon its objects will be meant either as a metaphysical or a merely causal dependence, ${ }^{35}$ thereby providing a stronger and a weaker form of this altogether weaker externalism, modal externalism rather than constitutive, or metaphysical, externalism: ${ }^{36}$ modal metaphysical externalism and modal nomological externalism

relation to objects, but a monadic property (ib., 118). Yet, since for him being about a merely intentional object amounts to be in relation with an intentional content (ib., 31-2), in his approach content plays precisely the role of an inner object. As a result, not only for Crane intentionality is ultimately relational, but his internalism turns out to be a variant of relational internalism.

${ }^{34}$ This possibility is envisaged in Edwards (1994, 17fn. 16). This is a weaker version already because it allows both for a neo-Fregean and for a neo-Russellean conception of a singular thought. Cf. fn. 3.

${ }^{35}$ For these distinct possibilities of intending a dependence relation, cf. again Thomasson $(1999,27-8)$.

${ }^{36}$ I borrow the terminological distinction between constitutive and modal externalism from Davies 2000. Yet I use it with some caution. In my opinion, insofar as essence is stronger than modality, constitutive externalism entails modal externalism but not the other way round. For Davies, on the contrary, the relevant entailments are just the opposite. Yet to my mind the fact that a thought depends on its objects for its existence does not yet show that it is constituted by it (as, e.g., the Neo-Fregean conception of object-dependent yet sense-constituted thoughts clearly shows: cf. fn. 3). Moreover, it is hard for me to see how an essential property can 
(whose respective negation will obviously constitute the corresponding weaker forms of internalism, modal metaphysical internalism and modal nomological internalism respectively). ${ }^{37}$ Another, even weaker, strategy holds that externalism and internalism are doctrines that respectively entail vs. do not entail the existence of any thing other than the subject to whom the thought is ascribed - simply and straightforwardly, if that thought exists, then, in the outer environment, there is vs. there is not something else over and above that thought. ${ }^{38}$ This strategy, therefore, amounts to defending an existential externalism and internalism respectively. Finally, as far as externalism is concerned, each of these strategies can be further be modulated both in a strong and in a weak form. The strong form states that the individuals whose existence is (necessarily or contingently) implied has to exist locally, i.e. in the vicinity of the thinker; the weak form gives up this 'locality' constraint.

Let me now wonder whether any of these alternatives fits reductionistic needs better. The answer is clearly affirmative. Take already the first main option, modal externalism vs. internalism. According to it, externalism is a dependence thesis that states that there is no thought if there is no such thing as its object. Now, as we have seen in Section 2, intentionality precisely consists in the thought-object dependence relation that is stated by that thesis. To be sure, as I have said, being a

fail to also be a necessary one. Davies adverts to dispositional properties and claims that, although these properties are externalistically individuated, Twin Earth duplicates may share them. Yet the fact that a property is described in externalist terms does not imply that it has an externalist nature. This may well be the case of dispositional properties, which indeed turn out to have an internalist character.

${ }^{37}$ The already cited doctrine of object-dependent thoughts defended by Evans 1982 is precisely a paradigmatic version of modal metaphysical externalism. Segal 2000 discusses (yet does not endorse) modal nomological externalism, by ascribing it to Fodor 1994.

${ }^{38}$ As Crane (forthcoming) reminds us, this is the point originally made by Putnam $(1975,220)$ in presenting methodological solipsism.

${ }^{39}$ In actual fact, McGinn $(1989,7)$ presents strong and weak externalism as two alternative externalist theses on the individuation conditions of a thought. Yet he also maintains that intentionality is an external relation. For, according to him, the first thesis says that the thought is individuated in terms of the object it is about, in the sense that it is causally related with. Yet we have seen before that the thesis that intentionality is an external relation is incompatible with the claim that externalism is a doctrine on the individuation conditions of a thought. 
dependence relation already makes intentionality a nonnatural property. Now I should put matters in more precise terms: intentionality is a nonnatural property if it is a metaphysical dependence relation, not if it is a nomological dependence relation. In actual fact, however, this specification is irrelevant. For, since in modal externalism in general intentionality no longer characterizes a thought essentially, by itself it does not prevent that thought from being token-identical with a certain physical state. Moreover, consider existential externalism vs. internalism, according to which externalism and internalism are respectively positive and negative theses on the mere, nonmodalized, existence-entailments of a thought. The existential externalist thesis limits itself to saying that, if the thought exists, in the outer world something else exists as well. Hence, this thesis is not forced to ascribe to that thought intentionality as a nonnatural property.

Given all this, it is natural for a reductionistically-oriented philosopher to give up the doctrine that externalism and internalism are (possibly opposite) metaphysical theses on the individuation conditions of a thought. This prompts the following, and last, question: is there any reason to hold that the constitutive, metaphysical, versions of externalism and internalism yield a better characterization of these doctrines than the alternative versions just sketched?

In actual fact, I think that there is one such reason. Up to now, we have only discussed of natural externalism, i.e., of the thesis - however further developed - that takes extramental worldly items as relevant for a thought. Yet, as everyone knows, natural externalism is flanked by social externalism, i.e., by the thesis - however further developed - that takes public meanings as relevant for a thought. ${ }^{40}$ Now, it seems to me that both natural and social externalism can be legitimately taken as species of externalism only if one endorses the thesis that externalism is a metaphysical doctrine on the individuation conditions of a thought. Whereas natural externalism states that the items the thought is about contribute to its individuation, socio-externalism states that the meanings of the language of the community a subject is embedded in contribute to the individuation of a thought.

Clearly, socio-externalism cannot be a mere thesis either on the necessary existence conditions of a thought or on the contingent existence-entailments of a thought. Definitely, it states more than the 
latter thesis. If one thinks that there are unicorns, according to socioexternalism this is the thought that there are unicorns if one is immersed in our linguistic community, but which turns out to be the thought that there are shunicorns if one is immersed in a linguistic community where 'unicorn' means shunicorn, an animal that is either a unicorn or a hyppogriph. To be sure, when socio-externalistically conceived, both the thought that there are unicorns and the thought that there are shunicorns respectively presuppose that there is an (actually different) public language ${ }^{41}$ Yet this does not mean to presuppose that there are certain things - unicorns and shunicorns respectively — outside that thinker. (As maintained by Burge onwards, socio-externalism is a doctrine that attempts at giving the content of de dicto, not de re, thoughts. $)^{42}$ So, existential externalism does not appear to capture socio-externalism. Moreover, socio-externalism also states more than modal externalism, the thesis on the necessary existence conditions of a thought. Clearly, as we have just seen socio-externalism entails that if there were no such a thing as a certain public meaning, there would not be the thought either. Yet it says more. According to socioexternalism, a subject $S$ 's thinking here and now that he has got arthritis in his thigh does not merely yield a thought that would not exist if 'arthritis' did not mean arthritis. For claiming this is compatible with holding that one such state is a thought whose constituents differ from the meanings that constitute the linguistic attribution of it, 'S thinks that he has got arthritis in his thigh.' (Put in Loar's terms, ${ }^{43}$ the claim that the thought that $S$ has got arthritis in his thigh would not exist if 'arthritis' did not mean arthritis would altogether become the thesis that the psychological content of a thought depends on its social content, taken as the meaning of the embedded part of the corresponding thought ascription.) Yet the thesis of socio-externalism is stronger than this. For, according to socio-externalism, the thought

${ }^{41}$ As Kim $(1996,199)$ suggests, socio-externalism presupposes that thought is derivative on public language.

${ }^{42}$ Literally speaking, it does not mean to presuppose the existence of other beings either, but only the possible existence of such beings. As Wittgenstein (1953, $\S \S 243,258$ ) has maintained, a language is public insofar as it might be understood by someone else, not insofar as it is so understood.

${ }^{43}$ Cf. Loar 1988. 
in question is precisely a thought that is constituted (among other things) by our meaning of 'arthritis.'

If both externalism and internalism are best characterized as metaphysical doctrines on the individuation conditions of a thought, however, for the reasons given in the previous Sections one has to admit that if one sticks to externalism - or to relational internalism for what matters - then reductionism with respect to intentional states has gone away. Perhaps not a bad consequence indeed. And, as we have seen in Section 2, maybe this is not even the last word in a thoroughly antinaturalistic direction. If intentionality is a nonnatural property, then it fails to supervene on physical properties. Thus, a state essentially having it cannot not only be token-identical with, but also supervene on, a physical state failing to have it essentially. ${ }^{44}$

\author{
Alberto Voltolini \\ Facoltà di Lettere e Filosofia \\ Università del Piemonte Orientale \\ via G. Ferraris 116, I-13100 Vercelli, Italy \\ albertov@lett.unipmn.it
}

References

Bach, Kent. 1987. Thought and Reference. Oxford: Clarendon Press.

Bonomi, Andrea. 1983. Eventi mentali. Milan: Il Saggiatore.

Burge, Tyler. 1979. Individualism and the Mental. Midwest Studies in Philosophy 4: 73-122.

Chomsky, Noam. 1992. Explaining Language Use. Philosophical Topics 20: 205-231.

Crane, Tim. 2001. Elements of Mind: An Introduction to the Philosophy of Mind. Oxford: Oxford University Press.

Crane, Tim. Forthcoming. Is Intentionality a Relation? Rabindra Bharati Journal of Philosophy (Calcutta).

Davidson, Donald. 1980a. Action, Reasons, and Causes. The Journal of Philosophy 60 (1963): 685-700; rpt. in Essays on Actions and Events. Oxford: Oxford University Press, 3-19.

Davidson, Donald. 1980b. Mental Events. In Experience and Theory, ed. by L. Foster, J.W. Swanson. Amherst: The University of Massachusetts Press (1970), 79-101; rpt. in Essays on Actions and Events cit., 207-227.

${ }^{44}$ I thank Diego Marconi as well as an anonymous referee of this journal for many helpful comments to previous versions of this paper. 
Davies, Martin. 2000. Externalism, Architecturalism, and Epistemic Warrant. In Knowing Our Own Minds, ed. by C. Wright, B.C. Smith and C. Macdonald. Oxford: Oxford University Press.

Descartes, René. 1985. Objections and Replies. in The Philosophical Works of Descartes, ed. by J. Cottingham, R. Stoothof, and D. Murdoch. Cambridge: Cambridge University Press.

Dretske, Fred. 1981. Knowledge and the Flow of Information. Cambridge MA: The MIT Press.

Edwards, Steve. 1994. Externalism in the Philosophy of Mind. Aldershot: Avebury.

Evans, Gareth. 1982. TheVarieties of Reference. Oxford: Oxford University Press.

Farkas, Katalin. 2003. What is Externalism? Philosophical Studies 112: 187-208.

Fine, Kit. 1995. Ontological Dependence. Proceedings of the Aristotelian Society 95: 269-289.

Fodor, Jerry A. 1982. Methodological Solipsism Considered as a Research Strategy in Cognitive Psychology. In Husserl, Intentionality and Cognitive Science, ed. by H. Dreyfus. Cambridge MA: The MIT Press, 277-303.

Fodor, Jerry A. 1987. Psychosemantics. Cambridge MA: The MIT Press.

Fodor, Jerry A. 1994. The Elm and the Expert. Cambridge MA:The MIT Press.

Gibbons, John. 1993. Identity without Supervenience. Philosophical Studies 70: 59-79.

Jacquette, Dale. 1994. Philosophy of Mind. Englewood Cliffs: Prentice-Hall.

Kim, Jaegwon. 1996. Philosophy of Mind. Boulder: Westview Press.

Kim, Jaegwon. 1998. Mind in a PhysicalWorld. Cambridge MA:The MIT Press.

Loar, Brian. 1988. Social and Psychological Content. In Contents of Thoughts, ed. by A.H. Grimm, D. Merrill. Tucson: The University of Arizona Press, 93-110, 121-138.

McDowell, John. 1998. Having the World in View: Sellars, Kant, and Intentionality. The Journal of Philosophy 95: 431-490.

McGinn, Colin. 1989. Mental Content. Oxford: Blackwell.

Millikan, Ruth G. 1984. Language, Thought, and Other Biological Categories. Cambridge MA: The MIT Press.

Mulligan, Kevin, Smith, Barry. 1986. A Relational Theory of the Act. Topoi 5: 115-130.

Putnam, Hilary. 1975. The Meaning of 'Meaning.' In Language, Mind, and Knowledge, ed. by K. Gunderson. Minneapolis: The University of Minnesota Press, 131-193.

Recanati, François. 1993. Direct Reference. Oxford: Blackwell.

Rosenkrantz, Gary. 1984. Nonexistent Possibles and Their Individuation. Grazer Philosophische Studien 22: 127-147.

Rosenkrantz, Gary. 1985/6. On Objects Totally Out Of This World. Grazer Philosophische Studien 25/26: 197-208.

Segal, Gabriel M. 2000. A Slim Book about Narrow Content. Cambridge MA: The MIT Press. 
Simons, Peter. 1983. Contents and Objects. In Epistemology and Philosophy of Science, ed. by P. Weingartner, J. Czermak. Vienna: Hölder-PichlerTempsky, 81-84.

Thomasson, Amie L. 1999. Fiction and Metaphysics. Cambridge: Cambridge University Press.

Voltolini, Alberto. 2000. Are All Alleged Possible Objects There? Topoi 19: 209-219.

Voltolini, Alberto. 2002. Why It Is Hard to Naturalize Attitude Aboutness. In Belief and Meaning, Essays at the Interface. Philosophical Analysis 3, ed. by W. Hinzen, H. Rott. Frankfurt a.M: Hänsel-Hohenhausen, 157-179.

Williamson, Timothy. 2000. The Necessary Framework of Objects. Topoi 19: 201-208.

Wittgenstein, Ludwig. 1953. Philosophical Investigations. Oxford: Blackwell. 